\title{
The role of plant-associated bacteria in the phytoremediation of heavy metal contaminated soils
}

\author{
Mengxuan Han ${ }^{1}$, Huan Yang ${ }^{1}$, Na Ding ${ }^{1}$, Shaohong You ${ }^{1}$, Guo Yu${ }^{1 *}$ \\ ${ }^{1}$ Guangxi Key Laboratory of Environmental Pollution Control Theory and Technology, Guilin University of Technology, Guilin, China
}

\begin{abstract}
Soil heavy metal pollution is an important environmental problem threatening people's health and sustainable economic development. Phytoremediation has become an important technology for the treatment of heavy metal contaminated soil with the characteristics of economy and environmental protection. This paper mainly analyzed the role of microbial community in heavy metal contaminated soil remediation process. Bacterias mainly strengthen the remediation effect of plants on heavy metal contaminated soil in two ways: first, bacterias have adsorption effect on heavy metals and reduce the toxicity of heavy metals to plants in soil; Two is to secrete organic acids and nutrients needed for plant growth to promote the absorption of heavy metals by hyperaccumulators.
\end{abstract}

\section{Introduction}

Soil is an important foundation for human survival and development, but soil heavy metal pollution has become a serious environmental problem. Soil heavy metal pollution is very common at home and abroad. Phytoremediation of soil pollution is usually closely related to plant rhizosphere bacterias. Therefore, the use of plant-bacteria combined remediation of heavy metal contaminated soil has also become a research hotspot in bioremediation, and has broad application prospects.

The current research results show that bacterias also have the ability to enrich a large number of heavy metals ${ }^{[1]}$, so the remediation of heavy metal contaminated soil by bacterias has become a hot issue. The cultivated land area polluted by different degrees in China has reached nearly 20 million $\mathrm{hm}^{2}$, which accounts for about $1 / 5$ of the cultivated land area. Heavy metals in soil can enter the food chain, threatening human health. Heavy metal contaminated soil has restricted the sustainable development of agriculture and economy. In recent years, phytoremediation technology has become a very promising treatment technology for soil heavy metal pollution due to its economy, green and environmental protection. However, the development of phytoremediation technology depends on the screening and growth of hyperaccumulators, and the treatment effect depends on the extraction and fixation effect of hyperaccumulators on heavy metals. At present, most hyperaccumulators have slow growth, long cycle, small biomass and metal selectivity, which restrict the development of phytoremediation technology. There are countless microbial communities in the soil, which are closely related to plants and affect the growth and metabolism of plants at all times ${ }^{[2]}$. Therefore, in the remediation process of heavy metal contaminated soil, microbial communities will also have a significant impact on soil remediation ${ }^{[3]}$. Exploring the role of microbial communities in the remediation process of heavy metal contaminated soil helps to enhance the remediation effect of heavy metal contaminated soil, and provides a theoretical basis for the future use of more effective remediation technologies for heavy metal contaminated soil.

\section{Role of microbial communities in the repair process}

\subsection{Microbial adsorption of heavy metals in soil}

Some bacterias in soil have the ability to tolerate or fix heavy metals. Due to the universality of bacteria, the ability to grow under controlled conditions and the adaptability to extensive environmental conditions, bacteria have strong tolerance to heavy metals in soil. For example, Pseudomonas, Enterobacter, Bacillus and Micrococcus cohn have excellent adsorption capacity for heavy metals ${ }^{[4]}$. The main reasons why some bacteria are resistant to the heavy metals are that they have highly adaptive ability to the environment, and some special proteins they have can bind to the heavy metals to form chelates, which will decrease their toxicity ${ }^{[5]}$. Bacterias chelate different parts of heavy metals in vivo. For example, $8.5 \%$ of $\mathrm{Pb}$ chelated by Bacillus subtilis is physically wrapped in the cell wall, $43.3 \%$ is maintained by ion exchange, $9.7 \%$ is combined with cell surface functional groups or precipitated on the cell surface, and $38.5 \%$ is accumulated in the cell[ ${ }^{6]}$.

Due to different growth conditions required by different bacterias, environmental factors often have a

*Corresponding author's e-mail: yuguo $@$ glut.edu.cn 
significant impact on the adsorption of heavy metals by bacterias ${ }^{[7]}$. Wang et al. ${ }^{[8]}$ found that when $\mathrm{pH}$ was too low, hydrogen ions competed with metal ions for bacterial surface adsorption sites, while when $\mathrm{pH}$ was too high, metal ions and hydroxide ions formed hydrated hydroxide precipitation. When $\mathrm{pH}$ is $5 \sim 6$, the adsorption effect of heavy metal ions on bacterial surface is the best. When the $\mathrm{pH}$ is too low, the heavy metal ions on the cell surface will be desorbed from the cell ${ }^{[9]}$. At the same time, the adsorption capacity of bacterias to heavy metals is limited. For example, Li et al. ${ }^{[10]}$ screened out 15 lead-tolerant strains, and found that the growth of a strain with $99 \%$ similarity to Escherichia fergusonii NBRC102419 on $1200 \mathrm{mg} / \mathrm{L}$ lead ion solid medium was significantly lower than that of the strain on $500 \mathrm{mg} / \mathrm{L}$ lead ion medium, indicating that concentration of heavy metal ions would hinder the growth and reproduction of bacteria. Therefore, the analysis of regional environmental factors and pollution types is an indispensable part of the remediation process of heavy metal contaminated soil by bacterias. The adsorption of heavy metals by bacterias is similar to the passivation of heavy metals by chemical passivators, the toxicity of heavy metals is reduced by surface adsorption or intracellular chelating. The reduction of available heavy metals in soil will reduce the harm of heavy metals to plants. Chemical passivators also reduce their toxicity by changing the forms of heavy metals in soil, so as to achieve the effect of repairing heavy metal pollution in soil.

\subsection{Bacterias promote uptake of heavy metals by hyperaccumulators and transfer to stems and leaves}

In addition to their own adsorption of heavy metals, bacterias can also promote the growth of hyperaccumulators and indirectly affect the remediation of heavy metal-contaminated soil ${ }^{[11]}$. Bacterias enhance the absorption of heavy metals by plants through the synthesis of iron carriers, acidification of soil, release of plant growth promoters and change of rhizosphere environment through redox ${ }^{[12]}$. Lampis et al. ${ }^{[13]}$ added the strains isolated from the contaminated area to the soil, and then used Pteris vittata L. for phytoremediation. The results showed that the strain had a certain resistance to arsenic, which could reduce arsenate to arsenate and promote the absorption and enrichment of arsenic by plants. Hyperaccumulators can help extract heavy metals by secreting low-molecular-weight organic chelating agents from roots, but they can only move heavy metals directly near their roots, while bacteria can transfer metals from soil far from rhizosphere and crystalline mineral phases.

Bacterias in soil mainly promote the growth of hyperaccumulators by releasing compounds beneficial to plants. For example, beneficial compounds produced by rhizosphere bacteria include enzymes, biosurfactants, iron carriers, nitric oxide, organic acids and antibiotics. These substances may help inhibit pathogenic and harmful organisms, improve mineral uptake, combine nitrogen fixation, enhance tolerance to abiotic stress or promote plant hormone production ${ }^{[14]}$. In addition, rhizosphere strains can dissolve inorganic phosphorus and mineralized organic phosphorus, and improve plant stress resistance, thereby promoting plant growth ${ }^{[15]}$. Zhao et al. ${ }^{[16]}$ applied microbial suspension to arsenic contaminated soil and used centipede grass to repair it. The results showed that the application of transgenic Streptomyces shf2 strain screened and domesticated had the best effect. The total plant biomass was $47.8 \%$ higher than that of the control, the arsenic content was $68.8 \%$ higher than that of the control, and the total arsenic accumulation was $136.0 \%$ higher than that of the control. The total plant biomass was $47.8 \%$ higher than that of the control, the arsenic content was $68.8 \%$ higher than that of the control, and the total arsenic accumulation was $136.0 \%$ higher than that of the control. Absorption and transportation of heavy metals by hyperaccumulators need to release organic acids to dissolve insoluble heavy metals in soil into ion forms that can be absorbed by plants ${ }^{[17]}$.Soil bacterias can secrete organic acids and other substances to dissolve heavy metals, which indirectly promote the extraction of heavy metals by hyperaccumulators. Yang et al. ${ }^{[18]}$ found that the mixed preparation of Bacillus megaterium and Bacillus mucilaginosus Krassilnikov can promote the absorption of cadmium, lead and zinc in Brassicajuncea L., and the preparation contains a variety of high concentrations of organic acids. These microbial metabolites activate heavy metals in soil, thereby promoting plant absorption and improving the efficiency of phytoremediation.

The effect of soil bacteria on plants is mainly on plant roots. Bacterias can affect the growth of roots ${ }^{[19]}$, and rhizosphere bacterias can also enhance plant resistance to pests and diseases ${ }^{[20]}$. Indoleacetic acid (IAA) is the main substance that bacterias have a major impact on plant growth. IAA produced by rhizobia interferes with the aboveground physiological process of plants by changing the plant auxin pool, while bacterial IAA increases the root surface area and length, thereby increasing the absorption of soil nutrients ${ }^{[21]}$. There are many ways of microbial synthesis of IAA, such as Erwinia herbicola, Rhizobium, Pseudomonas, Bradyrhizobium, Klebsiella, Azospirillum and Enterobacter, IAA formed by indole-3-pyruvic acid and indole-3-acetaldehyde was found, IAA formed by indole-3-acetamide was found in plant pathogenic bacteria such as Agrobacterium tumefaciens, Pseudomonas syringae and Erwinia herbicola ${ }^{[12]}$. Bacterias can not only change the material structure of soil and affect plants, but also change the root configuration of plants by changing the absorption of mineral nutrients, affecting the level and balance of plant hormones, and affecting the distribution of plant carbon nutrition ${ }^{[22]}$. The good growth of plants depends largely on the ability of roots to absorb soil moisture and nutrients ${ }^{[23]}$. It shows that bacterias have an impact on the phytoremediation process of heavy metal contaminated soil in many ways.

Different strains have different effects on the absorption of heavy metals by plants. Some strains can enhance the enrichment effect of heavy metals by promoting the growth of hyperaccumulators, and some strains can passivate heavy metals in soil to inhibit the absorption of heavy metals by plants ${ }^{[24]}$. Han et al. ${ }^{[25]}$ screened Bacillus megaterium and Serratia liquefaciens in soil with excessive lead and cadmium content contain 
urease synthesis gene ureC, which can secrete urease to improve the $\mathrm{pH}$ value of the solution and the mass concentration of $\mathrm{NH}_{4}^{+}$, thereby reducing the effective content of lead and cadmium in soil solution. Saravanan et al. ${ }^{[2]}$ found in the study of the effect of PAI5 (Gluconacetobacter diazotrophicus) on zinc morphology that endophytic bacteria could secrete 5 - ketoglutaric acid monoamide acid to improve the soluble zinc content in the environment. Sheng and $\mathrm{Xia}^{[27]}$ screened the Cd-resistant bacteria from soil can increase the content of dissolved $\mathrm{Cd}$ in soil, promote plant growth and increase Cd uptake after infection. He et al. also reported that Pseudomonas strain RJ10 (Pseudomonas sp.) and Bacillus strain RJ16 (Bacillus sp.) could increase the content of dissolved cadmium and lead in the environment, promote plant growth and improve the absorption of heavy metals.

Endophytic bacteria can not only increase the content of dissolved heavy metals, but also promote the absorption and transport of heavy metals to stems and leaves. The increase of heavy metal content in stems and leaves in phytoremediation projects will be conducive to pollution remediation. Most heavy metals are transferred in the form of organic compound. Various organic ligands secreted by endophytic bacteria can combine with heavy metals in vivo to change the speciation of heavy metals in plants and promote the transport of heavy metals to plants. Madhaiyan et al. ${ }^{[28]}$ used endophytic bacteria strains CBMB20 (Methylobacterium oryzae) and CBMB40 (Burkholderia sp.) to promote the transfer of nickel and cadmium to plant stems and leaves and increase the content of heavy metals in plant stems and leaves. Mastretta et al. ${ }^{[29]}$ also found that endophytic bacteria could increase the contents of $\mathrm{Cd}$ and $\mathrm{Zn}$ in tobacco.

\section{Conclusions and Perspectives}

Human survival and development is inseparable from the use and development of soil resources, and the degree of soil heavy metal pollution is still increasing, so soil remediation technology still has great development potential. Microorganisms, as long-standing organisms in soil, are closely related to plants. In the process of remediation of heavy metal contaminated soil, the effect of microorganisms on remediation of heavy metal contaminated soil must be considered. Soil environment is a complex ecological environment, and the effects of bacterias on plants are diverse and complex. Soil beneficial microorganisms improve the availability of plant nutrients in soil through their metabolic activities, change the physiological state of plant roots, and ultimately promote plant colonization, growth and development; Plants affect the community structure and metabolic activity of soil microorganisms through their rhizosphere secretion; Rotation is beneficial to the growth of soil beneficial microorganisms and can inhibit the accumulation of pathogens; The microbial species and structure in rhizosphere soil of plant communities may indicate the succession process of plant communities. It is a new direction of plant ecology and microbial ecology to reveal the succession law of plant communities by studying the composition and variation of rhizosphere microbial populations in different succession stages. Therefore, the role of bacterias in the remediation process of heavy metal-contaminated soil should be further studied from the following aspects: (1) The study of microbial function in the remediation process of heavy metal-contaminated soil can focus more on the interaction mechanism between plants and bacterias, and the relationship between rhizosphere bacterias and root exudates, as well as the process and principle of bacterias enhancing plant resistance and promoting plant absorption; (2) Bacterias exist in the soil environment for a long time and are complex and diverse, which are greatly affected by environmental factors, so remediation technology must consider the long-term impact on microbial communities; (3)Farmland is mainly used for crop cultivation, and the effects of microbial communities on crop yields need to be considered; (4) There are a large number of bacterias conducive to the remediation of heavy metal contaminated soil in nature, but there are also a large number of bacterias that pose a threat to human and animal and plant safety, so microbial selection is also a key link in the research process. The interaction between soil microorganisms and plants is not completely independent, but also affected by soil, temperature, moisture and other environmental factors. Further study on the relationship between plants, soil microorganisms and environment, especially the system composed of plants, soil and microorganisms, can provide more valuable information for future green agriculture, forestry protection and environmental protection.

\section{Acknowledgments}

The authors thank the financial supports from the Guilin Science and Technology Project (20190219-3).

\section{References}

1. M.X. Loukidou, K.A. Matis, A.I. Zouboulis, et al. Removal of As (V) from wastewaters by chemically modified fungal biomass. Water Res. J. 37, 45444552 (2003)

2. J.A. Krumins, N.M. Goodey, F. Gallagher. Plant-soil interactions in metal contaminated soils. Soil. Biol. Biochem. J. 80, 224-231 (2015)

3. M. Rajkumar, S. Sandhya, M.N.V. Prasad, et al. Perspectives of plant-associated microbes in heavy metal phytoremediation. Biotechnol. Adv. J. 30, 1562-1574 (2012)

4. A. Ayangbenro, O. Babalola. A new strategy for heavy metalpolluted environments: a review of microbial biosorbents. Int. J. Env. Res. Pub. He. J. 14, 94 (2017)

5. K.A. Mosa, I. Saadoun, K. Kumar, et al. Potential biotechnological strategies for the cleanup of heavy metals and metalloids. Front. Plant. Sci. J. 7, 303 (2016)

6. J. Bai, X. Yang, R. Du, et al. Biosorption mechanisms involved inimmobilization of soil $\mathrm{Pb}$ by Bacillus 
subtilis DBM in a multi-metal-contaminated soil. J. Environ. Sci. J. 26, 2056-2064 (2014)

7. A. Gupta, J. Joia, A. Sood, et al. Microbes as potential tool forremediation of heavy metals: a review. Microb. Biochem. Technol. J. 8(4):364-372 (2016)

8. Y.X. Wang, J.L. Guo, R.X. Liu, et al. Adsorption characteristics of microbial adsorbents for heavy metals. Environ. Sci. J. $72-75$ (2001)

9. G.Q. Zhou, Z.Y. Ren, H.Z. Yang, et al. Adsorption of $\mathrm{Cd}^{2+}$ and other heavy metal ions by microorganism Biotechnology bulletin, J. 155-159 (2013)

10. T.L. Li, H.J. Huang, Y. Peng, et al. Screening and adsorption of lead-resistant microorganisms. Journal of Anhui Agricultural University, J. 45, 696-702 (2018)

11. Y. Ma, Y.M. Luo, Y. Teng, et al. Rhizobacteria and its application in phytoremediation of contaminated soil. Acta Pedologica Sinica, J. 50, 1021-1031 (2013)

12. M. Seneviratne, G. Seneviratne, H. Madawala, et al. Role of rhizospheric microbes inheavy metal uptake by plants. Cham: Springer, J. 147-163 (2017)

13. S. Lampis, C. Santi, A. Ciurli, et al. Promotion of arsenic phytoextraction efficiency inthe fern Pteris vittata by the inoculation of As-resistant bacteria: a soil bioremediation perspective. Front. Plant. Sci. J. 6, 80 (2015)

14. Y. Ma, M.N.V. Prasad, M. Rajkumar, et al. Plant growth promoting rhizobacteria and endophytes accelerate phytoremediationofmetalliferous soil. Biotechnol. Adv. J. 29, 248-258 (2011)

15. M.S. Khan, A. Zaidi, P.A. Wani, et al. Role of plant growth promoting rhizobacteria in the remediation of metal contaminatedsoils: a review. Organic Farming, Pest Control and Remediation of Soil Pollutants, J. 8, 319-350 (2009)

16. G.C. Zhao, X.Y. Liao, X.L. Yan, et al. Study on accumulation ability of arsenic in soil by microorganisms. Environ. Sci. J. 31, 431-436 (2010)

17. K. Fischer, H.P. Bipp. Removal of heavy metals from soil components and soils by natural chelating agents Part II Soil extraction bysugar acids. Water Air Soil Poll. J. 138, 271-288 (2002)

18. Z. Yang, Z.L. Wang, B.W. Li, et al. Promotion effect of microorganism on phytoremediation of heavy metal contaminated soil. Chinese Journal of Applied Ecology, J. 20, 2025-2031 (2009)

19. E.M. Muehe, P. Igold, I.J. Aktylou, et al. pheremicrobial community composition affects cadmium and zinc uptakeby the metalhyperaccumulating plant Arabidopsis halleri. Appl. Environ. Microbiol. J. 2173-2181 (2015)

20. G.C. Zhao, J. Liang, J.Y. Dan, et al. Advances in relationship between soil microbes and plants. Southwest Forestry University. J. 31, 83-88 (2011)

21. S. Spaepen, J. Vanderleyden. Auxin and plantmicrobe inter-actions. Csh. Perspect. Biol. J. 3, a001438 (2011)
22. C. Ai, J.W. Sun, X.B. Wang, et al. Advances in relationship between plant rhizosphere sedimentation and soil microbes. Journal Of Plant Nutrition and Fertilizers, J. 21, 1343-1351 (2015)

23. W.L. Chen, J. LI, H.H. Zhu, et al. Advances in Rhizosphere Microbial Regulation of Plant Root Architecture. Acta Ecologica Sinica, J. 36, 5285-5297 (2016)

24. Y. Ma, M.N.V. Prasad, M. Rajkumar, et al. Plant growth promoting rhizobacteria andendophytes accelerate phytoremediation ofmetalliferous soils. Biotechnol Adv. J. 29, 248-258 (2011)

25. H. Han, X.Y. Wang, H. Cai, et al. Screening of heavy metal immobilization plant growth-promoting bacteria and its inhibition effect on heavy metal accumulation in wheat. Environ. Sci. J. 40, 33393346 (2019)

26. V.S. Saravanan, M. Madhaiyan, Thangaraju M., et al. Solubilization of zinc compounds by the diazotrophic, plant growth promoting bacterium Gluconacetobacter diazotrophicus. Chemosphere, J. 66, 1794-1798 (2007)

27. X. Sheng, J. Xia. Improvement of rape (Brassica napus) plant growth and cadmium uptake by cadmium-resistant bacteria. Chemosphere, J. 64, 1036-1042 (2006)

28. M. Madhaiyan, S. Poonguzhali, T. Sa. Metal tolerating methylotrophic bacteria reduces nickel and cadmium toxicity and promotes plant growth of tomato (Lycopersicon esculentum L.). Chemosphere Oxford, J. 69, 220-228 (2007)

29. C. Mastretta, S. Taghavi, D. Lelie, et al. Endophytic bacteria from seeds of nicotiana tabacum can reduce cadmium phytotoxicity. Int. J. Phytoremediat. J. 11, 251-267 (2009) 